\title{
Commercial fisheries in the Mediterranean, focusing on the environmental status and the corresponding management measures
}

\author{
Alexis Conides ${ }^{* 1}$ and Constantinos Papaconstantinou ${ }^{2}$ \\ ${ }^{1}$ Hellenic Centre for Marine Research, 46.7 km Athens-Sounion, 19013 Anabyssos Attilkis, Greece \\ ${ }^{2}$ Kolokotroni str., Penteli, Greece \\ *Corresponding author: Alexis Conides, Kolokotroni str., Penteli, Greece. Email: pap@hcmr.gr
}

Received: April 09, 2020; Accepted: April 15, 2020; Published: April 20, 2020

\begin{abstract}
The Mediterranean Sea is the largest semi-enclosed European sea with an area of 2.5 million $\mathrm{km}^{2}$ and bordered by 23 countries. The basin exhibits two openings, towards the Atlantic Ocean and towards the Indian Ocean through the Red Sea. It is known to be a sea rich in oxygen, oligotrophic and with higher salinity than other European marine waters. Its heterogeneity and isolation allowed the generation of a large number of habitats, leading to a high biodiversity and in turn, provision and sustenance of natural services and resources such as fisheries. Fisheries in the Mediterranean Sea are characterized by a fishing fleet of approximately 82000 vessels, of which small-scale accounts for $80 \%$ of the total. The total catch from the Mediterranean marine fisheries rose from 420,000 tonnes in 1950 to approximately 1,000,000 tonnes in the 1980s, with a peak of 1,093,000 tonnes in 1995. Ever since, the level of catches has been slowly decreasing until today. The total landed value follows a similar pattern, with a clear peak in 1985 at US\$ 3 billion followed by an almost-constant decrease trend, down to US\$ 1.5 billion. Mediterranean fishery sector is very important from the social and economic view of supporting small rural fisheries-dependent communities, without at the same time, being an important part of the agriculture GDP of the bordering countries. Most of these fisheries are exploited at an unsustainable level, which directly threatens stocks with overexploitation, increasing economic costs and employment losses and creating negative rents. Within a period of 15 years (1991-2006) overexploitation of the Mediterranean fishery resources reached $60 \%$ with negative effects mainly on benthic-pelagic species and apex predators (tunas etc.). This is evident mainly for the north Mediterranean countries due to technological progress and high investment values.
\end{abstract}

\section{Introduction}

The Mediterranean Sea is the largest $\left(2,969,000 \mathrm{~km}^{2}\right)$ and deepest (average 1,460 m, maximum 5,267 m) semi-enclosed European sea, consisting of two major interacting sub-basins, the western and eastern Mediterranean, connected by the Straits of Sicily with depth $\sim 350$ $\mathrm{m}$. The western basin is connected with the Atlantic Ocean through the Gibraltar Strait. The Ionian, Levantine, Adriatic and Aegean are located in the eastern basin, which communicates with the Black Sea through the Strait of Dardanelles and with the Red Sea through the Suez Canal. Several, smaller basins, are recognizable within the two main sections, which show remarkable differences in terms of general oceanographic conditions.

From the oceanographic point of view, which is a pressure to the fisheries state in the area, the Mediterranean Sea can be considered as comprising three main water masses.

a) the Atlantic Water, found in the surface layer, having a thickness of 150-200 $\mathrm{m}$ and characterized by a salinity of 36.2 \%o near Gibraltar to 38.6 \%oin the Levantine basin;

b) the Levantine Intermediate Water (the main water body of the Mediterranean) formed in the Levantine Basin, from the overlying Levantine Surface Water (LSW) lying in depth between 200 and $500 \mathrm{~m}$, and characterized by temperatures of 13-15.5 ${ }^{\circ} \mathrm{C}$ and salinity of 38.4-39.1\%o;

c) the Mediterranean Deep Water formed in both the western and eastern basins; the Eastern Mediterranean Deep Water (EMDW) is characterized by a temperature of $13.6^{\circ} \mathrm{C}$ and a salinity of $38.7 \%$.

It is known that the Mediterranean Sea is a sea rich in oxygen, poor in nutrients and saltier than other European seas. The Mediterranean Sea as a whole has been referred as an "evaporated basin" since surface evaporation, particularly in the Levantine region, accounts for this net inflow, and more than compensates for the inflow of lower salinity water from Black Sea, rivers and other freshwater inflows dominated by discharges, primarily of the rivers Po, Rhone, Nile and Ebro. The biological productivity of the Mediterranean is among the lowest in the world. Average primary production in the western basin corresponds to an assimilation of $50 \mathrm{gCm}^{-2} \mathrm{y}^{-1}$ [1] while in the eastern basin the primary production amounts to about $26 \mathrm{Cm}^{-2} \mathrm{y}^{-1}[2]$. Primarily productivity can, however, be unusually high at mouths of the rivers and at urban centers.

\section{Specificities of the Mediterranean Sea}

The Mediterranean Sea has a very distinct geographical, climatic 
and biological nature that makes it very different from other sea basins. Its heterogeneity and isolation have generated a great number of habitats, which lead to a high biodiversity spot.

\section{Biological Specificities}

a) Biodiversity: in the Northern Hemisphere, marine biodiversity increases from the North Pole toward the equator. This is reflected in a greater number of commercial species in the Mediterranean Sea, with generally smaller individuals compared with the EU waters in the North Atlantic.

b) Increased complexity of the marine ecosystem: This is the direct result of a greater number of species, with greater potential interactions between them as well.

c) Presence of invasive species: while this can also be found in other closed or semi-closed seas such as the Baltic Sea, it is a very common phenomenon in the eastern Mediterranean, with a high number of invasive species coming from the Red Sea through the Suez Canal.

\section{Governance Specificities}

a) Shared stocks: Because of the distribution of territorial waters, most of the surface of the Mediterranean Sea is made up of international waters and most commercial fish stocks are shared with other coastal states, many of which are not part of the EU. This shared responsibility increases from west to east and not so much from north to south.

b) International management of fisheries: Fisheries on shared stocks are managed by two regional fisheries organizations:

- International Commission for the Conservation of Atlantic Tunas (ICCAT) for highly migratory species (these count for more than $10 \%$ of the value of the total catches in the Mediterranean)

- General Fisheries Council for the Mediterranean (GFCM) for other species.

The political context can also make disciplined management difficult in cases of political instability (wars, post-war situations, migratory movements, etc.).

\section{Specificities in fleet composition and fleet activity}

a) Daily activity of boats: the vast majority of Mediterranean fishing vessels come back to port every day, generally with catches mixing several species. As each species is usually below the $50 \mathrm{~kg}$ threshold set by the Control Regulation, the catches are not declared.

b) Fleet composition: most of the vessels composing the Mediterranean fleet are less than $10 \mathrm{~m}$ long and therefore not covered by the rules on registering catches. As a result, many catches are unrecorded. Small-scale operations involving small vessels with low daily catches represent $80 \%$ of the Mediterranean fishing fleet, $60 \%$ of jobs and $23 \%$ of landings.

c) Economic performance: the 2015 Annual Economic
Report noted a progressive deterioration in the economic performance of the small-scale coastal fleet. In sharp contrast to many EU fleets of other regions, which showed steady improvement, EU fleets in the Mediterranean region did not improve their economic performance significantly over the 2008-2013 period.

\section{Effects of human activities on the marine ecosystem}

Human socioeconomic activities along the Mediterranean coastline have been identified as pressures that lead to the degradation of the marine environment.

a) Pollution: Reduction of fish stocks due to localized pockets of pollution (in areas with strong human concentration and improper waste treatment).

b) Traffic: there is heavy maritime traffic (particularly south of Sicily and in the Alboran Sea).

c) Highly climate change: Mediterranean is a vulnerable region, with expected shifts on species' distribution and fish population dynamics, and introduction of invasive species

d) Biological blooms: there is a relatively high number of algal and jellyfish blooms, which may change the flux of energy of the food web (e.g. greater predation of fish food, eggs or larvae)

e) Top-predators: there is a decline in certain populations of toppredators, notably sharks, which otherwise help adjust the balance between fish populations.

\section{Mediterranean biodiversity}

Mediterranean Sea exhibits a high diversity of habitats, both pelagic and demersal. Most of these habitats (bathyal, mesopelagic or bathypelagic) are poorly known in relation to coastal and continental shelves ecosystems, which are more easily surveyed, while at the same time there is a relatively good knowledge of their commercial species stock status, by means of fisheries surveys and commercial captures. Some 12.000 marine species are counted in the Mediterranean Sea, while many of them are introduced. The number of introduced species (NIS) in the Mediterranean has increased spectacularly since the start of the last century. How many species are recent arrival? NIS enter the Mediterranean Sea mainly via the Suez Canal (actively or passively), but also via Gibraltar and Dardanelles through shipping (ballast water, fouling) and aquaculture (EEA 2006). Until the mid-20th century, the NIS introduction, establishment, and expansion rates were low. This number begins to increase at the last decade of the century, mainly because of the water temperature and salinity barriers between the Red Sea and the Mediterranean Sea [3-5]. Extrapolating from initial surveys of selected taxonomic phyla an overall estimate of about 1,000 invaders may not be unrealistic [6]. Following Zenetos [7] the number of reported alien species in the Mediterranean, reached 903 by April 2008 and 947 by October 2009 while the estimate of Galil [8] is of 573 species, 80 species introduced in the period 2000-2007. The lower level of biodiversity, at least as far as species diversity is concerned, in the eastern Mediterranean reflects a general trend of biodiversity 
reduction in the Mediterranean Sea from the West to the East, given that the conditions of the Levantine Basin are not conducive for the thriving of the Atlantic contingent, being so biased by a founder effect.

The Suez Canal, the Gibraltar Strait, and the Marmara Strait constitute a corridor going through different species from Red Sea, Atlantic Ocean and Black Sea respectively. A lot of marine species moving from Atlantic Ocean in the Mediterranean Sea through the Gibraltar Strait and established, mainly, in its western basin, where the faunistical and hydrological parameters are almost similar between the two areas, while a smaller number of species arrived the eastern basin. The Indo-Pacific and Erythrean origin marine species, which migrate to the Mediterranean through the Suez Canal, named Lessepsian immigrants. The main abiotic difference between the Red Sea and the Mediterranean is the temperature regime, which is stable in the tropical Red Sea, but appears wide fluctuations in the subtropical Mediterranean. Finally, some species migrate from Black Sea established mainly in the Aegean Sea, which act as a barrier for their ongoing distribution.

The fauna of the Mediterranean Sea is mainly temperate Atlantic origin with the Gibraltar Strait to be an important gate for the Atlantic originated fish species distribution in the Mediterranean Sea. On the other hand, tropical Indo-Pacific origin fishes from Red Sea entered in the eastern Mediterranean through the Suez Canal. This eastern region captures less than half of the known Mediterranean species diversity, with $43 \%$ of the total listed Mediterranean species. The ichthyofauna of the Eastern Mediterranean began to be actively studied only the last fifty years. Thus, it should be stressed that the inventory of the fishes in the area has been a matter of discussion only in the last four or five decades, in spite of the studies carried out during international scientific expeditions in the beginning of the twentieth century.

Several lists concerning the number of Mediterranean fish has been completed the last 50 years. Tortonese [9] registered 543 species in his list, including 579 species (501 Osteichthyes and 78 Chondrichthyes) in a later revision [10]. Quignard [11] lists a total of 562 species, while Whitehead et al. mention 589 species. Fredj and Maurin [12] list a total of 612 species ( 30 uncertain). Quignard \& Tomasini [13] increased the number at 664 species. According to the data available by Psomadakis et al. [14], the Mediterranean fish diversity can be summarized as follows: 602 (including subspecies) bony fish species (Osteichthyes), 79 cartilagineous fish species (Chodrichthyes) and 3 cyclostomes (Agnatha); making a total of 684 species, belonging to 173 families (147 Osteichthyes, 24 Chodrichthyes, 2 Agnatha).

\section{Mediterranean living resources}

\section{Management of the fisheries resources}

The Mediterranean Sea (GFCM - major fishing area 37) have sustained important fisheries activities since ancient times. Since the Mediterranean Sea is semi-enclosed sea, with an overall lack of exclusive economic zones (EEZs) and consequently with stocks that are often shared among fleets from different countries, the fishery sector has always played an important role in the region. Today, industrial, semi-industrial and small-scale fisheries coexist in the region, using a large variety of fishing gear. In contrast with other major fishing areas, Mediterranean Sea fisheries generally lack large mono-specific stocks, and instead exploit a variety of benthic and pelagic stocks of fish, as well as mollusks and crustaceans. In fact, despite its relatively low economic output compared to other economic activities in the region (e.g. tourism, oil and gas exploration), the annual production of roughly 1.12 million tonnes offers employment opportunities to several hundred thousand people, supplies seafood products for human consumption to local and regional markets, and creates many other indirect benefits, maintaining the social fabric of coastal communities. Fisheries are also an intrinsic part of the cultural landscape of Mediterranean Sea.

In the Mediterranean is essential the absence of the knowledge of the stock status as well as complete or independent information on fishery mortality, biomass estimation or other biological or management parameters. Lleonart [15] describing the fisheries assessment methodologies applied in the Mediterranean, concluded that the most fisheries research projects have a local contingency. The methods that have been using so far (technical measures, the recently established landing obligations, national management plans) are only good as 'preventive' measures. Even the 'symptomatic treatments' that occasionally administer (EU multiannual plans, GFCM management plans) take a long time to produce effects and anyway do not eradicate the 'disease.' To treat the causes of this problem and reverse the steady decline of fish stocks, needs a proper cure. In this case the cure consists of immediate, exceptional measures at both EU and international level. Such measures need to be embraced by all Mediterranean countries in unison and need to take into account the economic risks as well as the environmental ones.

Knowledge of the status of the fish stocks is a prerequisite for the implementation of the management measures applied in the Mediterranean Sea. The first organize research effort named Mediterranean Trawl Survey (MEDITS) and organized and carried out by France, Greece, Italy and Spain at 1994 [16] funded from the EU. The MEDITS survey program at the beginning intended to produce basic information on benthic and demersal species in terms of population distribution as well as demographic structure on the continental shelves and along the upper slopes at a global scale in the Mediterranean. Nevertheless, the intention was to organize the protocols in such a way as to easily permit the enlargement of the program to other Mediterranean countries. One of the mail challenges of the project was the adoption of common standardized sampling protocols. The four first partners early in 1994 just before the first survey have adopted the basic protocols. These protocols included the design of the survey, the sampling gear, the information collected, and the management of the data as far as the production of the common standardized analyses of the data. The manual has been established from different experiences and particularly from that of the IBTS Group [17]. The protocols have been amended for the following surveys, and particularly in 1995 to take into account the experience gained during the first survey.

In 2002, the European countries bordering the Mediterranean made a commitment to curry out MEDITS surveys yearly according to Data Collection Framework (DCF). Permanent links were organized 
with the relevant EU bodies, such as the Regional Coordination Group of the Mediterranean and Black Sea and the Scientific and Economic Committee for Fisheries (STEFC). Thus, the program has been integrated as an indispensable obligation of all EU countries in all the community seas, in the context of the implementation of the Common Fisheries Policy (CFP). Links were also maintained with the General Fisheries Council for the Mediterranean (GFCM), the FAO regional fisheries management organization. The strength of the MEDITS surveys so far has been the agreement among the participants to share standardized methods as a Mediterranean level using the same gear, sampling scheme and protocols for collecting, checking and analyzing data. From 2008 the program was extended to include the small-scale fisheries and the small pelagic. At that time all the protocols changed in order to include all the new information with common methodologies e.g. small-scale fisheries with different fishing gear and small pelagic by acoustic methodologies. The program is commitment of all the Mediterranean countries, at the same time, similar programs are being implemented by all EU member states covering their surrounding seas. The program is constantly updated with new information aimed at a better management of fish stocks e.g. more target taxonomic categories and fish species, data collection on marine macro-litter, etc.

Recognizing the importance and peculiarities of fisheries in the Mediterranean, and the need for strong regional cooperation, the GFCM was established to promote the development, conservation, rational management and best utilization of living marine resources in the region. Among its various responsibilities, the GFCM since 1970, periodical updating of the research activities dealing with demersal and small pelagic Mediterranean living resources during working group occasions and technical consultation at a region level. The GFCM Data Collection Reference Framework (DCRF) is the first GFCM framework for the collection and submission of fisheriesrelated data in the GFCM area of application. FAO fisheries statistics data based has now uploaded until 1994. All this allows to draw a fairly complete panoramic synthesis of this situation. Time series of fisheries landings can provide important information for changes in a fishery, or changes to the underlying environment [18]. Often, as in the case of Mediterranean fisheries, this is essential in the absence of complete or independent information such as on the fishing intensity or fishing mortality affecting the stock. Mediterranean fisheries are now confronted with serious challenges originating from environmental impacts of coastal activities, climate change, over exploitation of fishery stocks and poor management of the shared resources [19].

It underpins the formulation of sound scientific advice by relevant GFCM subsidiary bodies (i.e. Scientific Advisory Committee on Fisheries), ultimately supporting the GFCM decision-making progress towards sustainable Mediterranean fisheries. Formalized in 2017, the DCRF covers in a standardized and optimized way catch (landing and catch per species), fishing fleet operating in the GFCM fisheries restricted areas, fishing effort (per fleet segment, fishing gear) socioeconomic data, and biological information such as stock assessment, length, size at first maturity, European eel abundance. The last years GFCM regularly reviews the state of fisheries, including the economic and social aspects of the fishing industry, as a basis for the formulation of scientific and management advice conducive to sustainable and responsible fisheries.

The scientific knowledge of large pelagic stocks and fisheries is annually updated for more than 40 years by International Commission for the Consultations of Atlantic Tunas (ICCAT). In general, EU catch limits or quotas are not applicable in the Mediterranean, with the exception of limits on Bluefin tuna that have been introduced in response to recommendations by the ICCAT for the protection of shared stocks.

In order to study, understand and implement the biodiversity and habitat productivity objectives in the Mediterranean, which are essential elements in ecosystem fisheries management of an extensive sea region, all states bordering the Mediterranean should organize and implement common management measures to control fishing. These measures should aim at protecting and conserving fishery resources, including legislation requiring the licensing of fishing vessels and regulating the characteristics and use of fishing gear. In addition, almost every Mediterranean country has designated marine or specially protected areas (although varying by type and objectives) and/or had adopted temporal closures to protect, in part, certain species during their reproductive period. Other management tools in use include total allowable catches (TAC) or quotas for large pelagics, minimal landing sizes, protected species and limits on the days at sea. Legislation regarding the treatment of by-catch is rare in the Mediterranean although this is to be expected given its mixed fisheries. Other than licensing, rights or incentive-adjusting measures are infrequently used.

Fisheries management is conducted by regional bodies based on data and scientific advice, and control measures to ensure that rules are applied fairly to and complied with by all fishermen. Intense international cooperation encourages all countries bordering the Mediterranean Sea to play by the same rules. However the European Commission believes an extra effort by all is now required. To avoid the collapse of fish stocks and its impact on the ecosystem, and to guarantee a future for the fisheries industry in the region, all Mediterranean countries need to act urgently and collectively.

CFP was first enforced in the 1970s and has been successively updated in 2002 and recently in 2014. The CFP keystone is the sustainable exploitation of marine resources both in environmental and socio-economic terms toward a dynamic fishing industry and ensuring a fair standard of living for fishing communities. The current CFP specifies that between 2015 and 2020 exploitation will be conducted according to MSY objectives based on the consensus that this strategy will maintain fish stocks in the long term. The impact of fishing on the marine environment is not fully comprehended and for this reason, CFP adopts a precautionary approach based on selective fisheries practices and a total ban of discards. Similarly, the Marine Strategy Framework Directive [20, 21] requires EU Member States to take measures to achieve Good Environmental Status (GES) of all European marine waters by 2020 .

From the management perspective, Mediterranean countries limit their management plans mainly to control fishing effort and 
fishing capacity together with specific technical measures, such as gear regulation (mainly mesh size and net configuration, as for example for the purse seine), establishment of a minimum conservation reference size, and closures of areas and seasons for fishing to control which vessels have access to which waters and areas. Moreover, the Article 19 of Council Regulation 1967/2006 foreseen that management plans within their territorial waters are adopted for trawling and other fishing activities. In this context, it is important to notice that spatial and temporal closures apply mainly to trawls, which are prohibited within 3 nautical miles from the coast or within the $50 \mathrm{~m}$ isobath, where this is closer to the coast. Also, temporal closures regard bottom and mid-water trawl nets are mainly enforced for 30-45 days during summer (Demestre et al., 2008). A second set of management measures in the Mediterranean Sea incorporate the establishment of permanent marine protected areas. Apart from the general absence of catch limits, in all other respects the region is subject to the same type of EU management measures as the rest of the EU, including requirements relating to the EU vessel register, licensing, monitoring and control arrangements, and new data collection measures.

\section{State of fish stocks}

Based on different documents that have been submitted to the GFCM Technical Consultation, as well as on the 65-year-time series of landings in the Mediterranean some general observations can be reached for the West and the East Mediterranean (a) despite some significant differences, the overall pictures from the West to East Mediterranean are not strikingly different, (b) from the study of the trends, it is clear that a high proportion of species or species groups in both Mediterranean basins have shown increases in landings over the whole period; either of these increases were linear, or concave upwards or concave downwards, and (c) from the perspective of stock assessment, very few time series show stable yield levels, suggesting a considerable dynamism caused by environmental and/or trophic or fishery-related impacts in the fisheries of the sub-region.

According to the scientific advice, the large majority of fish stocks assessed are shrinking and some are on the verge of depletion. All in all, only $9 \%$ of fish stocks assessed are fished at levels below MSY levels [20] (COM (2016) 396). Despite recent improvements, the number of stocks whose status is unknown remains still large. For fish stocks such as hake, red mullet, anglerfish and blue whiting, current fishing mortality rates have been more than six times higher than MSY. These species represent around $43 \%$ in volume of the total reported trawl catches of the EU fishing fleet (source: STECF and GFCM reports). Fishermen themselves report that they catch fewer and fewer fish every year, with potentially serious repercussions on the industry's performance and on the economy of coastal communities. There are several reasons for the poor state of fish stocks, with the most important the overfishing, while pollution and climate change certainly play a role, there can be no doubt that extensive overfishing is one of the key causes. The EU has been using a number of methods to counter overfishing: EU countries have been reducing their fleets and our legislation features national and international fisheries management plans, catch limitations and environmental requirements.

Fisheries provides around 314000 direct jobs (www.fao.org). Total landings in the Mediterranean Sea increased irregularly from about to 900000 tonnes in 1970 to almost 1750000 tonnes in 1982 (Figure 1). Total landings remained relatively stable during most of the ' $80 \mathrm{~s}$ before declining abruptly at the end the decade largely due to the overfishing of pelagic fisheries. There is an increased in landings until 1994, reaching 1.087.000 tonnes, continuing with a limited increase to 1200000 tonnes in 2000 . In the following years until 2005, the landings appear slightly up and down fluctuations since 2007 showing the maximum 1.300 .000 tonnes until today. In the coming years, there is a continuous increase of 900000 tonnes in 2014. This production remains almost constant until 2018, with a modest increase of 930000 tonnes in 2016 (Figure 1).

In the GFCM Mediterranean area, the ranking of capture fisheries production in 2014-2016 dominated by Turkish production, followed by Italy, Algeria and Greece maintained almost the same percentage in landing contribution, while Tunisia and Croatia show an increase compared. Total annually landings for Spain slightly decreased between 2014 and 2016. Despite the long-term upwards trends, the short-term trends over the last 4 years (2014-2017) tell a different story. One tentative explanation is that multispecies landings may now be approaching a peak for the Mediterranean as a whole, with new increases (especially in South and East Mediterranean) being balanced by recent declines, especially in the West and North basins. (Table 1) (Figure1).

Table 1. Landings by major groups of species between 2014 and 2016 in GFCM and Black Sea.

\begin{tabular}{|c|c|c|c|c|}
\hline \multirow[b]{2}{*}{ Group of species } & \multicolumn{4}{|c|}{ Landings (tones) } \\
\hline & 2014 & 2015 & 2016 & contribution average values (\%) \\
\hline Herrings, sardines, anchovies & 518248 & 693966 & 576341 & 48,7 \\
\hline Miscellaneous coastal fishes & 142160 & 152776 & 162137 & 12,5 \\
\hline Miscellaneous pelagic fishes & 84482 & 78503 & 80487 & 6,6 \\
\hline Squids, cuttlefishes, octopuses & 52602 & 50132 & 50525 & 4,2 \\
\hline Clams, cockles, ark shells & 40963 & 56808 & 43413 & 3,8 \\
\hline Shrimps, prawns & 39810 & 44664 & 44407 & 3,5 \\
\hline Marine fishes not identified & 51875 & 38537 & 34273 & 3,4 \\
\hline Cod, hakes, haddocks & 37625 & 40031 & 38219 & 3,2 \\
\hline Shads & 13127 & 21515 & 23704 & 1,6 \\
\hline Others & 136312 & 137861 & 183583 & 12,5 \\
\hline Total & 1117204 & 1314793 & 1237089 & \\
\hline
\end{tabular}



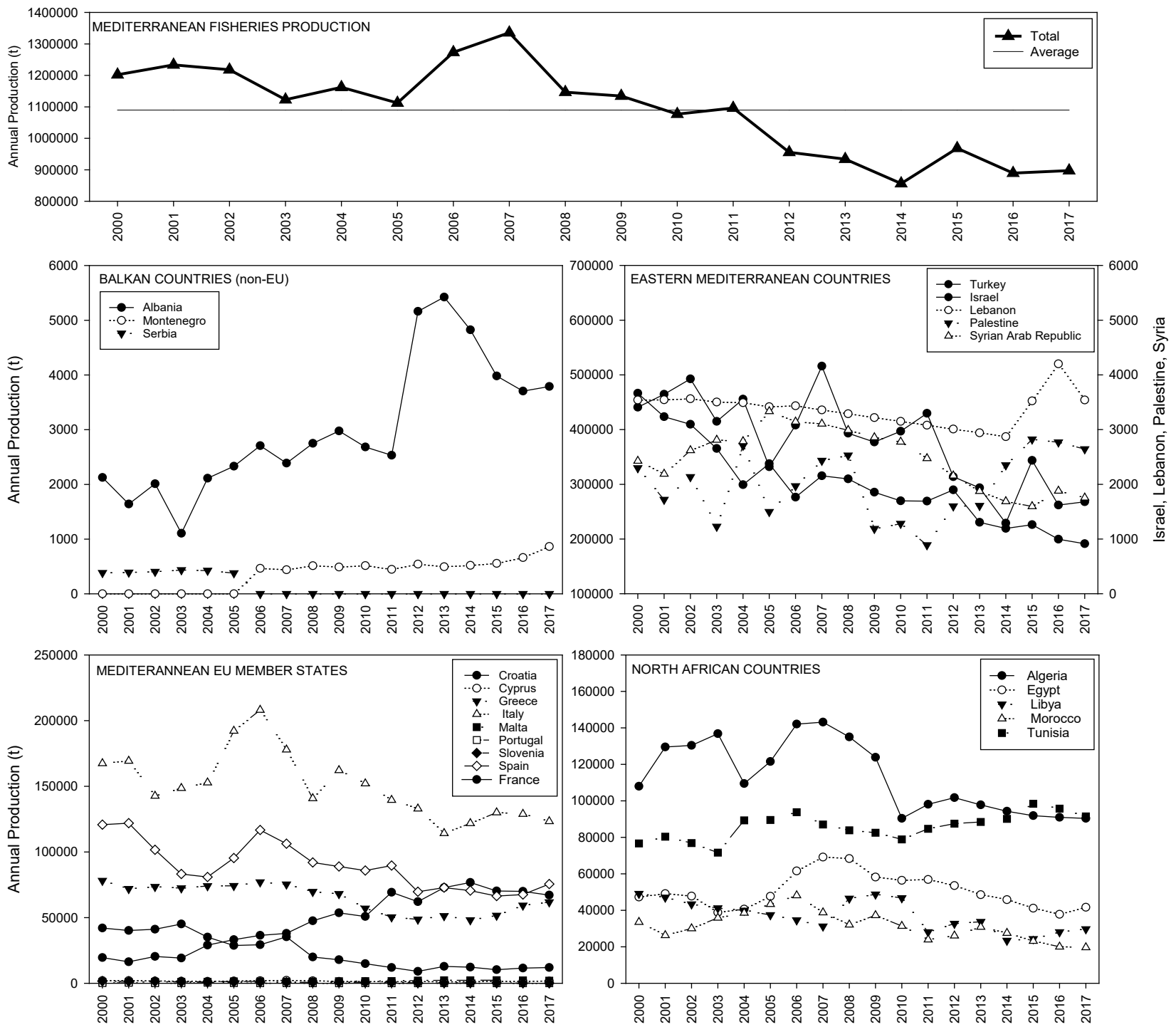

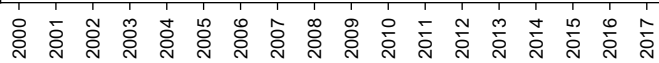

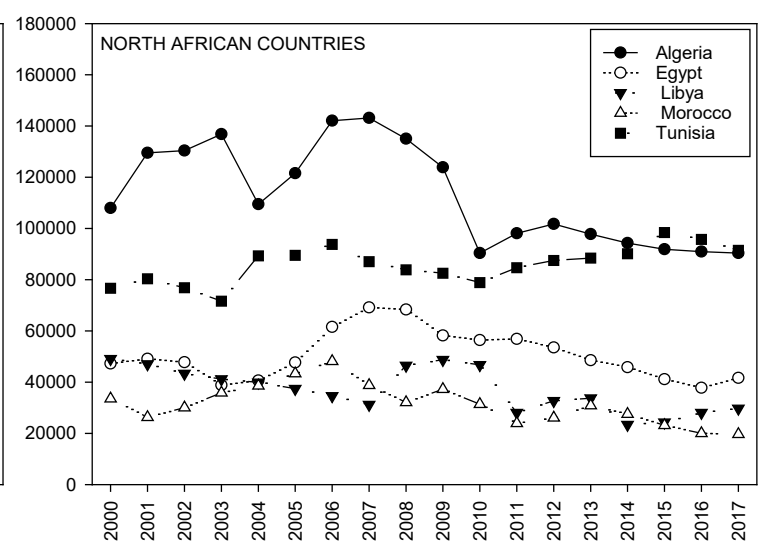

Figure 1. Annual fluctuation of fishing landings in the Mediterranean Sea since 2000 as a whole and by geographical areas.

Compared with the whole GFCM area including and the Black Sea, the main groups of species contributing to landing in the whole area are very similar. Nonetheless, the contribution of small pelagic species (e.g. sardines, anchovies, sprat, etc.) is slightly less important (48\%) of the total landings, while the contribution of the other group species is slightly higher. In comparison with the average landings of the last three years in the Mediterranean and Black Sea (Table 1), the main groups of species contributing at least to $1 \%$ of the catches remain stable. According to GFCM [18] there groups of species, namely "herrings, sardines, anchovies" (596000 tonnes), "Miscellaneous coastal fisheries" (152400 tonnes) and "Miscellaneous pelagic fishes" (81000 tonnes), constitute around $69 \%$ of the total reported landings in the entire GFCM and Black Sea area. Six other groups of species contributing to more than $1 \%$ of the landings amount to $20 \%$ of the total landings, and the constitution of all remaining species amount to approximately $12 \%$ overall.

\section{The Mediterranean Fishing Fleet}

Fisheries in the Mediterranean Sea are characterized by a fishing fleet of approximately 75.000 vessels at 2017-2018 where small- scale accounts for $80 \%$ of the total (though these numbers should be considered an underestimation). In the area, fish stocks are exploited by EU fishing vessels almost exclusively in the northwestern Mediterranean (e.g. the Balearic Islands, the Gulf of Lion, Corsica, Sardinia and the Ligurian and Tyrrhenian Seas) and in the north Adriatic Sea, while the central Mediterranean (e.g. the Strait of Sicily and the Ionian Sea) and the eastern Mediterranean (e.g. the Aegean Sea and the Levantine Sea) are jointly exploited with non-EU countries.

The Mediterranean fisheries according to EU regulations can be broken down into three main categories: (a) small-scale fisheries, (b) trawling and (c) seining fisheries. The term "small-scale fisheries" attempting to integrate aspects of the "coastal" and "artisanal" fisheries and to avoid the vagueness, inconsistencies and differences of the previous definition, is virtually absent from the official terminology of the most Mediterranean countries. This term was introduced at first at 1990 by the European Commission, when the commission presented 
a proposal (COM (90) 358 final of 7 September 1990) [18] to amend Regulation $4028 / 86$ on measures to improve and structures in the fisheries and aquaculture sector.

GFCM proposed the following fleet segments for data reporting purpose; (a) Polyvalent (P), small-scale vessels without engine using passive gear, small-scale vessels with engine using passive gear and Polyvalent vessels; (b) Seiners (S), Purse seines and Tuna seiners; (c) Dredgers (D); (d) Trawlers (T), Beam trawlers, Pelagic trawlers and Trawlers; (e) Longines (L).

Official statistics from 2017-2018 for the total fisheries fleet suggest that in the GFCM Mediterranean countries appear 74.748 fishing units (Table 2), of which $74,8 \%, 8,3 \%, 4,6 \%$ and $4 \%$ are registered as Polyvalent, Trawlers, Purse Seiners and unallocated fishing vessels respectively [19]. A number of 62201 coastal vessels equipped with the above fishing gear, together with the dredgers and longliners operate in all the countries of the Mediterranean Sea. A number of 6183 trawlers operate in the Mediterranean and most of them could be considered as semi-industrial or industrial vessels, taking into account the international practice. The purse seines, one of the main fishing gear used in the area, amount 3423 vessels and are distinguished into two major types: purse -seines operating during the day and purse -seines operating during the night. There are no significant differences between the two types as far as equipment and their activity focus on different species. Concerning the total distribution of the Mediterranean fishing fleet, there and vessel construction are concerned. The difference is that they employ a different fishery methodology, are no significant differences between the Eastern $(30,6 \%)$ and Central (30,5\%) Mediterranean and less in the Western $(20,0 \%)$ and Adriatic Sea (14,2\%). The number of operating fishing vessels by a group of fleet segment in the different GFCM Mediterranean countries are presented in Figure 2.

According to the most-up-to-date GFCM information, the capacity of the operating fishing vessels in the Mediterranean is about 769000 GT and 4720000 kilowatts (KW) unevenly distributed among the various countries, with four of them, Turkey (19,7\%), Italy (16,2\%), Egypt $(13,7 \%)$ and Tunisia $(11,3 \%)$ holding about $60 \%$ of the total fishing capacity. Other national fleet with substantial capacity (more than 50000 GT) are those of Greece, Algeria and Spain. (Figure 3)

The evolution of the number and GT of the fishing fleet in Mediterranean Countries between 1970 and 1995 is summarized in Table 2 (source: FAO-FIGIS/Fisheries Global Information System). Of the data processed this way (Table 2), it can be concluded that until the beginning of the 1990s an expansion of the effort took place regarding vessels, and the capacity of Mediterranean fishing fleets of the countries analyzed. From the mid-1990s both dimensions started to decrease although, this reduction is especially important in fleets operating in other seas, such in the case of France, Spain and Morocco.

\section{Employment}

The human dimensions of Mediterranean fisheries are as complex

Table 2. Fluctuation of Number of vessels and total tonnage between 1970 and 1995 (FAO-FIGIS).

\begin{tabular}{|l|c|c|c|c|c|}
\hline & 1970 & 1975 & 1980 & 1985 & 1990 \\
\hline Number of vessels & 56.936 & 61.970 & 68,515 & 72,976 & 86.272 \\
\hline Total tonnage (GT) & 1.538 .195 & 1.860 .553 & 2.084 .836 & 2.101 .905 & 82.004 \\
\hline
\end{tabular}

Purse Seines

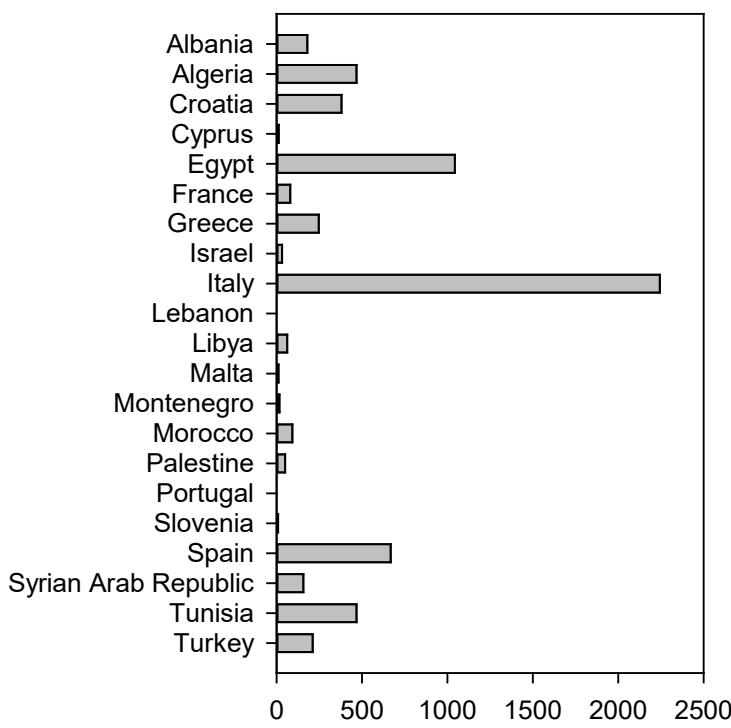

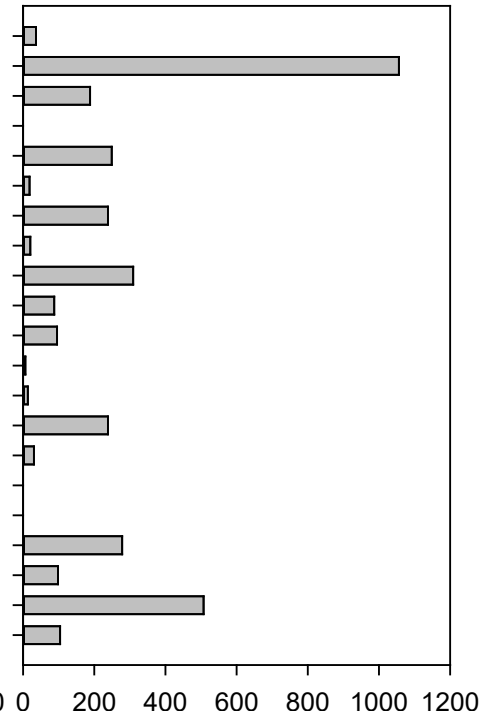

Number of Vessels (2017-18)
Coastal

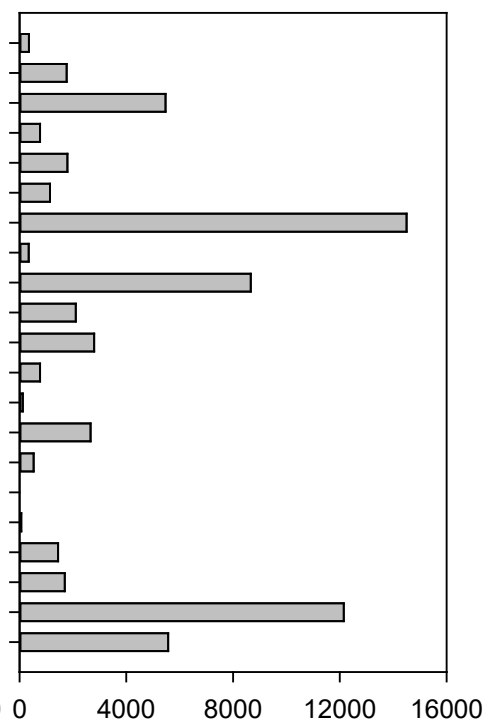

$\left.{ }^{*}\right)$ The coastal category includes polyvalent, dredgers and longline vessels.

Figure 2. Number of operating fishing vessels grouped by fleet segment (2017-2018) in the different GFCM Mediterranean countries. 

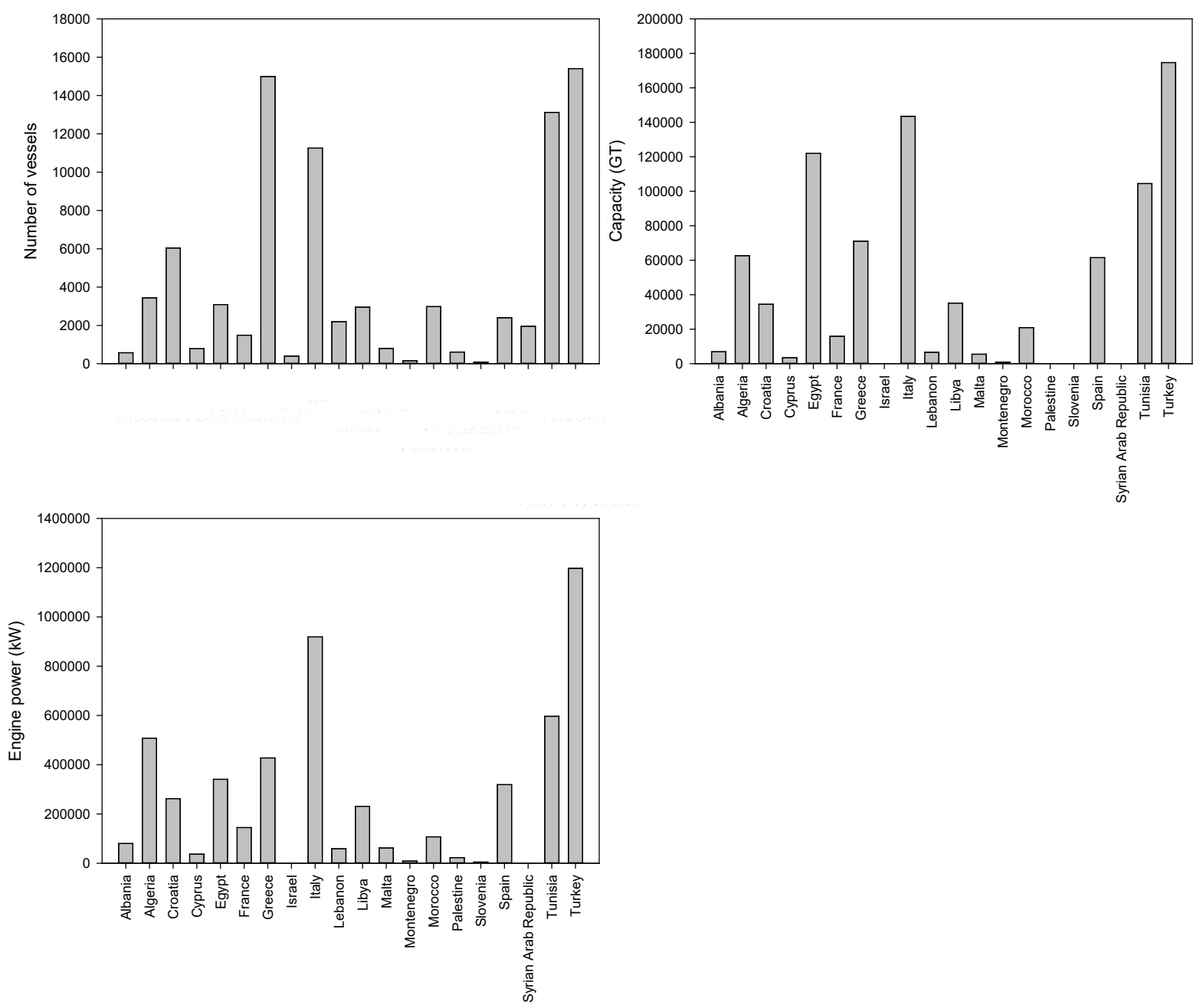

Figure 3. Number, capacity (GT) and kilowatts (KW) of operating fishing vessels by GFCM Mediterranean countries (2017-2018).

and divers as the species and the ecosystems upon which they depend. For example the Mediterranean states' economies range from lowincome food-deficit to highly developed, their coastlines from deserted to heavily urbanized, and their fisheries from unindustrialized and labor intensive to modern and capital intensive.

Although often overlooked in the statistics, these fisheries are important for the welfare of coastal inhabitants as well as job and income security. They also act synergistically with other activities (tourism, recreation etc.). According to GFCM and DCRF data collection program, total employment onboard fishing vessels for the Mediterranean account for 227250 jobs, an increase by $10 \%$ since 2016, while 900.000 others are employed in related services and industries. Four countries in the region represent $55 \%$ of all employment onboard fishing vessels: Tunisia, Turkey, Algeria and Italy (Figure 4).

FAO [19] estimates that pre- and post-harvest labour, gleaning activity or other in-kind labour, such as support from family members may account for an additional 50\% in employment figure (approximately additional 25000-26000 people) [22]. The central, eastern and western Mediterranean subregions jointly represent $85 \%$ of all employment onboard fishing vessels in the GFCM area of

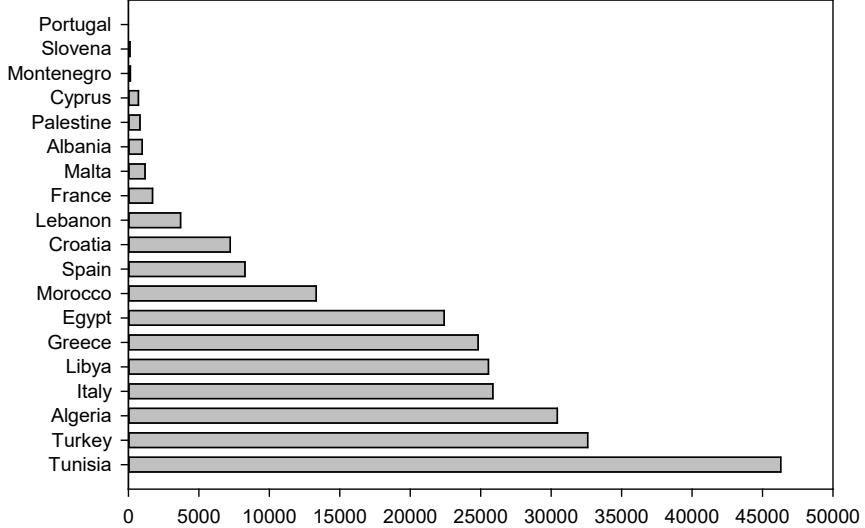

Figure 4. Onboard fishing vessel employment per Mediterranean State (these figures do not include pre- and post-harvest labor, gleaning activity or other in-kind labor, such as support from family members)

application.

Small-scale fisheries is a very important segment for the Mediterranean for job and income security of the fisheries dependent coastal communities. Even though, SSF accounts for $26 \%$ of total 


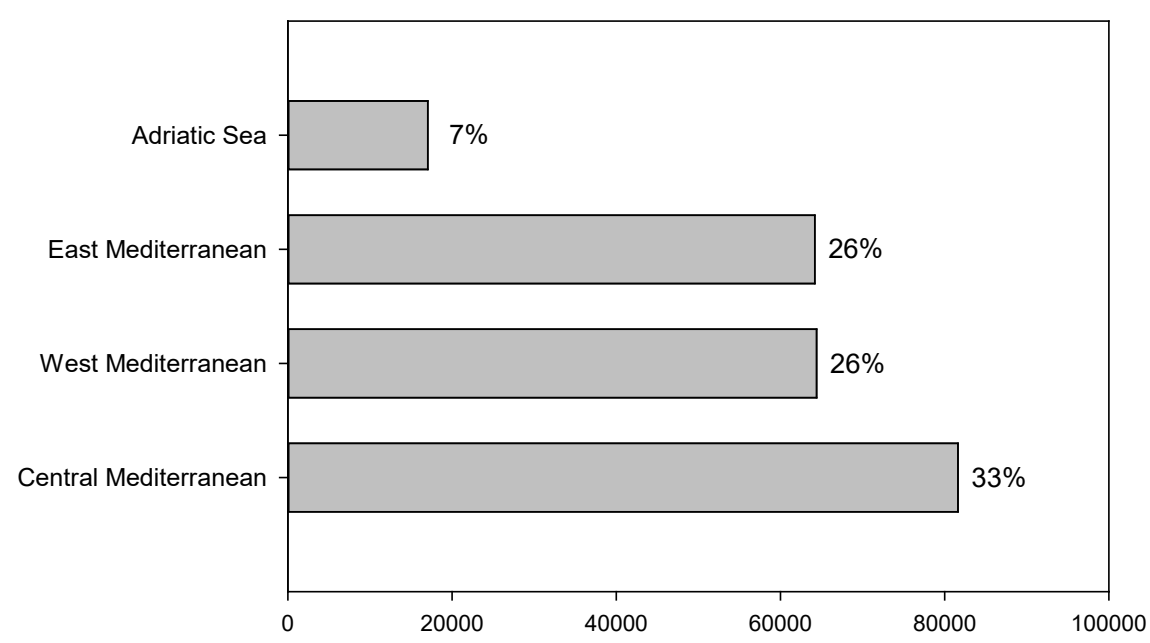

Figure 5. On-board fishing vessel employment (numbers and percent) per Mediterranean sub-region

revenues of the region, they provide employment for the 59\% of the total people working in the Mediterranean fisheries sector (approximately 135000 persons on board SSF vessels). SSF as a source of employment is more important for the Central Mediterranean region where it resents $75 \%$ of all on vessel employment. In the other Mediterranean regions (West, East Mediterranean and Adriatic Sea), $54 \%$ and $46 \%$ (on average) of the employment is offered by industrial fisheries and small-scale fisheries respectively (Figure 5).

\section{Specific Case: The exploitation of tuna}

The exploitation of tuna is one of the oldest and most complex fishing activities of the Mediterranean. It is practiced on a species of very high economic value whose main target is the Japanese markets, and this causes a strong fishing effort. Tuna is a trans-zonal species swimming in international and national waters of many countries and in large aggregates of individuals, which facilitates its location and capture on a large scale. It should be noted that tuna is characterized by complex breeding, low maturation and by being vulnerable to reductions in their feed (small pelagic) and very much affected by overfishing. Taking into consideration all these factors, it is easy to understand the critical situation of these resources. The ICCAT regulates the Bluefin tuna fishery, of which the EU and its Member States are members.
The source of information on production/capture data reported in Table 6 is FISHSTAT, and due to the characteristics of this fishery, the reliability and coverage of these data are limited. This circumstance also makes it difficult to determine these catches used for fattening. In accordance with available statistics, production of tunas, bonitos and billfishes in the Mediterranean Sea has been decreasing since the year 1995 (Table 6), after various decades of expansion. The expansion of production that took place between 1975 and 1985, when it more than doubled, has proved to be unsustainable. Amongst the species exploited, we could highlight the Atlantic Bonito, Atlantic Bluefin tuna and Swordfish. These three species account for $90 \%$ of the total capture of these large pelagic in the Mediterranean; some 130,000 $t$ in 2005 (Table 3).

Today the situation is changed and bluefin tuna is indeed a primary example of sustainable management, having gone from heavy over-exploitation to full recovery in the space of a few years thanks to a massive international effort led by the EU. The European Commission is pleased with the work and commitment of the Member states to ensure compliance with the rules in this fishery in the past few years, and is also appreciative of the significant role played by the European Fisheries Control Agency in ensuring the coordination of these controls. It will remain vigilant to ensure that all rules, and particularly the individual vessels' quotas, are fully respected. Will be

Table 3. Capture production (in tonnes) of tuna fishes in the Mediterranean and Black Sea by species (all countries included).

\begin{tabular}{|c|c|c|c|c|c|}
\hline Species & 1975 & 1985 & 1995 & 2000 & 2005 \\
\hline Albacore & 500 & 4,129 & 1,587 & 5,578 & 3,657 \\
\hline Atlantic bluefin tuna & 11,266 & 19,296 & 37,560 & 23,106 & 23,886 \\
\hline Atlantic bonito & 6,038 & 18,487 & 15,371 & 18,760 & 77,460 \\
\hline Atlantic white marlin & & & 1 & 1 & \\
\hline Frigate and bullet tuna & 2,644 & 5,240 & 5,205 & 2,763 & 3,029 \\
\hline Little tunny (=Atlantic Black skipjack tuna) & 1,386 & 2,040 & 1,894 & 3,298 & 1,660 \\
\hline Marlins, sailfishes, etc. & & & 1 & 1 & 50 \\
\hline Plain bonito & & 9 & 115 & 145 & 5 \\
\hline Skipjack tuna & 6 & 13 & 43 & 90 & 29 \\
\hline Swordfish & 4,304 & 15,293 & 12,432 & 15,570 & 14,582 \\
\hline Tuna-like fishes nei & 780 & 2,125 & 1,264 & 3,353 & 4,739 \\
\hline TOTAL & 26,924 & 66,632 & 75,473 & 72,665 & 129,097 \\
\hline
\end{tabular}


continued to monitor catches and analyze Vessel Monitoring System data (a satellite-based control system) on a constant basis and will continue to send out inspectors.

Following advice from ICCAT scientists in 2014, ICCAT has agreed to an increase of $60 \%$ of the Total Allowable Catch (TAC) over three years $(2015,2016$ and 2017) [23-25]. In 2016, this brings the European TAC to 11203 tonnes. The quota is shared between the $8 \mathrm{EU}$ countries actively involved in the bluefin tuna fishery (Spain, France, Italy, Croatia, Greece, Portugal, Malta, and Cyprus), with Spain and France having the largest shares.

To this date, it is the only stock in good state in the Mediterranean, while a great majority of stocks remains overfished. To ensure that no overfishing takes place and similarly to previous years, a strict control and inspection program are in place: it sets concrete control priorities and benchmarks and deploys a significant number of inspectors, patrol vessels and aircraft, all coordinated by the European Fisheries Control Agency and the Member States concerned. For the first time in 2016, ICCAT is also implementing the eBCD, a new state-of-the-art electronic tuna catch document system which greatly improves the traceability of all bluefin tuna products. The use of this program, combined with the rest of the measures of the recovery plan, makes this fishery one the most controlled in the world, and provides the best guarantees to consumers that the resource is being used sustainably.

\section{References}

1. Margalef R (1985) Introduction to the Mediterranean, In: Western Mediterranean, (R. Margalef Ed.) Pergamon Press, Oxford. 1-16.

2. Dugdale RC and Wilkerson FR (1988) Nutrient sources and primary production in the Eastern Mediterranean. Oceanologica Acta 9: 179-184

3. Papaconstantinou C (1990) The spreading of Lessepsian fish migrants into the Aegean Sea (Greece). Scientia Marina 54:313-316.

4. Galil BS (2007) Loss or gain? Invasive aliens and biodiversity in the Mediterranean Sea. Marine Pollution Bulletin 55:314-322.

5. Zenetos A, Meric E, Verlaque M, Galil P, Boudouresque CF, et al. (2008) Additions to the annotated list of marine alien biota in the Mediterranean with special emphasis on Foraminifera and Parasites. Mediterranean Marine Science 9: 119-165.

6. Galil BS, Froglia C, Noel P (2002) CIESM Atlas of Exotic Species in the Mediterranean. Crustaceans: decapods and stomatops 2: 192.
7. Zenetos A (2010) Trend in aliens species in the Mediterranean. An answer to Galil (2009) Taking stock: inventory of alien species in the Mediterranean Sea». Biological Invasions 12: 3379-3381.

8. Galil BS (2009) Taking stock: inventory of alien species in the Mediterranean Sea Biological Invasions 11: 359-372.

9. Tortonese E (1958b) Elenco dei Leptocardi, Ciclostomi, Pesci cartilaginei ed ossei del Mare Mediterraneo. Atti Società Italiana Di Scienze Naturale E Museo Civico Di Storia Naturale di Milano 97: 309-345.

10. Tortonese E (1987) Pesci del Mediterraneo. Recenti studi intorno alla sistematica e distribuzione. Quaderni dell' Istituto di Idriobiologia e Acquacoltura 'G. Brunelli', Numero Speciale: 111

11. Quignard JP (1978) Introduction à l'ichtyologie méditerranéenne: aspect général edu peuplement. Bulletin de l'Office National des Pêches, Tunisie, 2 : 3-21.

12. Fred, $G$ and Maurin, C (1987) Les poissons dans la banque de données MEDIFAUNE. Application a létude des caractéristiques de la faune ichthyologique méditerranéenne. Cybium 11: 217-302.

13. Quignard JP, Tomasini JA (2000) Mediterranean Fish Biodiversity. Biologia Marina Mediterranea $7: 1-66$.

14. Psomadakis PN, Giustino S, Vacchi M (2012) Mediterranean fish biodiversity: an updated inventory with focus on the Ligurian and Tyrrhenian seas. Zootaxa 3263: 1-46.

15. Lleonart J (1997) Critical review of methodology, 40-51. In: Coordination of fisheries research in the Eastern Mediterranean, (G. Tserpes Ed.), IMBC \& EE/DG XIV: 75

16. Betrand JA, De Sola LG, Papaconstantinou C, Relini G and Souplet A (2002) The general specification of the MEDITS surveys. Scientia Marina (Suppl.2) 9-17.

17. ICES (1992) Reports of the ICES Advisory Committee on Fishery Management.

18. Caddy JF (1990) Recent trends in the fisheries and environment in the General Fisheries Council for the Mediterranean (GFCM) Studies \& Reviews 66: 142.

19. FAO (2018) The state of Mediterranean and Black Sea fisheries. General Fisheries Commission for the Mediterranean Rome, 172.

20. UNEP/MAP/Plan Bleu (2013) Greening the Mediterranean fisheries: tentative assessment of the economic leeway. Technical Report, Plan Bleu: 42

21. European Commission (2016) Consolidated treaties, charter of fundamental Rights. European Council 412.

22. Sauzade D, Rousset (2013) Greening the Mediterranean fisheries: tentative assessment of the economic leeway. Plan Bleu, Valbonne, France.

23. EEA (2006) Annual Report. European Environmental Agency, Copenhagen.

24. Papaconstantinou C, Farrugio H (2000) Fisheries in the Mediterranean Mediterranean Marine Science 1: 5-18.

25. Spedicato MT, Massuti E, Merigot B, Tserpes G, Jadaud A and Relini G (2019) The MEDITS trawl survey specifications in an ecosystem approach to fishery management. Scientia Marina 83S1 : 9-20. 